\title{
Gabapentin Versus Tricyclics for Neuropathic Pain
}

\author{
Alec B. O'Connor, MD, MPH \\ University of Rochester School of Medicine and Dentistry, Box MED/HMD, Strong Memorial Hospital, Rochester, NY, USA.
}

$\mathrm{J}$ Gen Intern Med 24(6):780-1

DOI: $10.1007 / \mathrm{s} 11606-009-0957-1$

(c) Society of General Internal Medicine 2009

$\mathrm{T}$ o the Editor: Chou and colleagues are to be commended for tackling a challenging and important subject with their detailed meta-analysis comparing gabapentin with tricyclic antidepressants for the treatment of neuropathic pain. ${ }^{1}$ The authors argue that prior analysts have over-emphasized the strength of the evidence derived from indirect metaanalysis. I believe that Chou and colleagues have overemphasized the strength of evidence derived from direct meta-analysis in this case.

The authors' direct meta-analysis relies on three head-tohead randomized clinical trials (RCTs) comparing gabapentin to tricyclic antidepressants. However, one of these trials, ${ }^{2}$ clearly identified as "an open-label pilot study," should not be included simply because it lacks any attempt at blinding. Blinding is considered to be a critical component of good RCT design because trials in which patients or investigators are aware of their treatment allocation are more likely to produce biased results than blinded studies, especially in trials with subjective outcomes like pain. ${ }^{3,4}$ Bias for gabapentin would be especially likely within an open-label trial that occurred during a remarkably intense and elaborate marketing campaign. ${ }^{5}$ This might explain the extraordinary response to gabapentin in this trial $(85 \%)$, which was the only head-to-head trial showing a better response to gabapentin than to tricyclics.

Without the open-label trial, there are two small head-tohead trials comparing gabapentin with two different tricyclic antidepressants in two different neuropathic pain conditions. One of these trials, using a crossover design with only 21 patients, found a higher response rate for amitriptyline $(67 \%$ vs. $52 \%$ ), though the difference was not statistically significant. ${ }^{6}$ The other trial, using a parallel group design, found similar outcomes for gabapentin and for nortriptyline. ${ }^{7}$ Neither trial was adequately powered to detect differences between active treatment arms. Neither trial included a placebo comparison to ensure assay sensitivity (i.e., that the trials had the ability to distinguish between active and inactive treatments), which is "essential to the interpretation of" trials comparing active treatments. ${ }^{8}$

The authors' analysis does not include unpublished trials. The promotion of gabapentin was subsequently shown to be extraordinarily comprehensive, and included deliberate suppression of negative clinical trials results. ${ }^{5}$ At least one large (325 patients), multi-center double-blind RCT studying

Published online April 7, 2009 gabapentin in patients with painful diabetic neuropathy is known to have remained unpublished, almost certainly because the highest dosage studied $(2400 \mathrm{mg} / \mathrm{d})$ failed to show a better analgesic response for gabapentin (30\%) than for placebo $(25 \%, \mathrm{P}>0.05){ }^{9}$ It is certainly possible that additional negative trials for gabapentin, some possibly comparing gabapentin to tricyclics, also remained unpublished. The authors also did not include an unpublished double-blind parallel group RCT comparing amitriptyline to pregabalin and to placebo in 254 patients with painful diabetic neuropathy (extensive detail is provided about this trial by the US FDA). ${ }^{10}$ This trial showed a higher response rate for amitriptyline $(47 \%)$ than for pregabalin $(40 \%)$ or placebo $(30 \%, \mathrm{P}<0.05$ for placebo comparison with amitriptyline but $\mathrm{P}>0.05$ for placebo comparison with pregabalin; no comparison between amitriptyline and gabapentin is provided).

Chou and colleagues have also over-represented the response rate to gabapentin in one of the trials. They report that 17 of 19 patients treated with gabapentin achieved a good analgesic response, but the published report of this trial indicates that there were 19 gabapentin-treated patients in the first crossover period. ${ }^{11}$ There were a total of 40 gabapentin-treated patients, so the true response rate to gabapentin in the trial was $17 / 40$ (43\% rather than $90 \%$ ).

If one does not include the open-label trial then the head-tohead trials tend to favor tricyclics, but there does not seem to be enough data to conduct a meaningful meta-analysis. As the authors report, indirect meta-analysis favors tricyclics through a broad range of sensitivity analyses, and inclusion of the unpublished trial data and reduction of the response rate in the gabapentin trial described above may tilt the balance further in favor of tricyclics. The authors argue that more head-to-head trials are needed, which is certainly true. ${ }^{12}$ Until there are adequately powered and designed head-to-head double-blind RCTs, the best relative ranking of efficacy seems to come from the indirect meta-analyses, despite the limitations the authors describe in their manuscript.

Corresponding Author: Alec B. O'Connor, MD, MPH; University of Rochester School of Medicine and Dentistry, Box MED/HMD, Strong Memorial Hospital, 601 Elmwood Ave., Rochester, NY 14642, USA (e-mail: alec_oconnor@urmc.rochester.edu).

\section{REFERENCES}

1. Chou R, Carson S, Chan BKS. Gabapentin versus tricyclic antidepressants for diabetic neuropathy and post-herpetic neuralgia: discrepancies between direct and indirect meta-analyses of randomized controlled trials. J Gen Intern Med. 2009;24:178-88.

2. Dallocchio C, Buffa C, Mazzarello P, Chiroli S. Gabapentin vs. amitriptyline in painful diabetic neuropathy: an open-label pilot study. J Pain Symptom Manage. 2000;20:280-5. 
3. Chow SC, Liu JP. Randomization and blinding. In Design and Analysis of Clinical Trials. Hoboken, New Jersey: John Wiley \& Sons, Inc.; 2004.

4. Boutron I, Estellat C, Guittet L, et al. Methods of blinding in reports of randomized controlled trials assessing pharmacologic treatment: a systematic review. PLoS Med. 2006;3:1931-9.

5. Steinman MA, Bero LA, Chren MM, Landefield CS. Narrative review: the promotion of gabapentin: an analysis of internal industry documents. Ann Intern Med. 2006;145:284-93.

6. Morello CM, Leckband SG, Stoner CP, Moorhouse DF, Sahagian GA Randomized double-blind study comparing the efficacy of gabapentin with amitriptyline on diabetic peripheral neuropathy pain. Arch Intern Med. 1999;15916:1931-7.

7. Chandra K, Shafiq N, Pandhi P, Gupta S, Malhotra S. Gabapentin versus nortriptyline in post-herpetic neuralgia patients: a randomized, double-blind clinical trial-the GONIP trial. Int $\mathrm{J}$ Clin Pharm Ther. 2006;44:358-63.
8. Temple R, Ellenberg SS. Placebo-controlled trials and active-control trials in the evaluation of new treatments. Part 1: ethical and scientific issues. Ann Intern Med. 2000;133:455-63.

9. Backonja M, Glanzman RL. Gabapentin dosing for neuropathic pain: evidence from randomized, placebo-controlled clinical trials. Clin Ther. 2003;251:81-104.

10. FDA Center for Drug Evaluation and Research. Approval package for: application number 21-446 medical review(s). (Accessed February 11, 2009 at http://www.fda.gov/cder/foi/nda/2004/021446_Lyrica\% 20Capsules_medr.PDF.)

11. Gorson KC, Schott C, Herman R, Ropper AH, Rand WM. Gabapentin in the treatment of painful diabetic neuropathy: a placebo controlled, double blind, crossover trial. J Neurol Neurosurg Psychiatry. 1999;662:251-2.

12. Dworkin RH, O'Connor AB, Backonja M, et al. Pharmacologic management of neuropathic pain: evidence-based recommendations. Pain. 2007; 132:237-51. 